\title{
LOCAÇÃO SOCIAL NO CENTRO HISTÓRICO DE BELÉM: investigação introdutória
}

\author{
Simaia do Socorro Sales das Mercês* \\ Helena Lúcia Zagury Tourinho** \\ Marco Aurélio Arbage Lobo ${ }^{* * *}$
}

\begin{abstract}
Neste artigo, busca-se iniciar discussão sobre a possibilidade de utilização da locação social como modalidade de provisão de moradia digna no Centro Histórico de Belém. Para isso: a) analisa-se a locação social em políticas habitacionais brasileiras; b) identifica-se e quantificase, para o Centro, a demanda potencial oriunda do déficit habitacional e a oferta potencial baseada nas hipóteses de adaptação de imóveis desocupados e subutilizados e de construção de unidades habitacionais em lotes vazios e com ruínas. O estudo conclui que há, em princípio, oferta suficiente para atender à demanda do Centro e de outras áreas da cidade. Entretanto, ressalta que para a efetivação dessa oferta, é necessário superar vários entraves. Por fim, alerta que o aluguel social em centros históricos, além de política de provisão de moradia, configura uma política de conservação do patrimônio histórico e cultural, o que agrega benefícios a serem contabilizados como resultado da política proposta.

PALAVRAS-CHAvE: Política Habitacional. Locação social. Centro Histórico de Belém.
\end{abstract}

\section{INTRODUÇÃO}

A subutilização do solo e de imóveis bem localizados nas cidades brasileiras é recorrentemente apontada, na literatura especializada, como um dos problemas urbanos a serem enfrentados pelas políticas públicas. Por outro lado, é conhecido o volume do déficit habitacional e o enorme contingente de pessoas que "resolve" suas necessidades de moradia por meio da ocupação de áreas e (ou) imóveis inadequados. Sob princípios de justiça social, e no âmbito restrito da política urbana, fo-

* Doutora em Arquitetura e Urbanismo. Especialista em Planejamento e Administração de Transporte Urbano . Professora do Núcleo de Altos Estudos Amazônicos (NAEA) da UFPa.

Rua Augusto Corrêa, no 1, Setor Profissional. Guamá. Cep: 66075900. Belém - Pará - Brasil. simrcs@yahoo.com.br

* * Doutora em Desenvolvimento Urbano. Professora e pesquisadora do Programa de Mestrado em Desenvolvimento e Meio Ambiente Urbano e do curso de graduação de Arquitetura e Urbanismo na Universidade da Amazônia. Av. Alcindo Cacela, 287. Umarizal. Cep:66060-902. Caixapostal: 1757. Belém - Pará - Brasil. helenazt@uol.com.br

*** Doutor em Desenvolvimento Socioambiental. Professor titular da Universidade da Amazônia (UNAMA). Técnico de nível superior do Instituto Brasileiro de Geografia e Estatísticas (IBGE).

Av. Alcindo Cacela, 287 / SUPES. Umarizal. Cep: 66060000. Belém - Pará - Brasil. lobo2502@gmail.com ram incluídos, no arcabouço legal vigente no país, dispositivos destinados a balizar o uso da propriedade urbana, buscando sua submissão a uma função social.

No caso das áreas centrais, em especial nos centros históricos, o problema da subutilização e da não utilização de imóveis assume características peculiares, visto que ocorre em áreas de elevada acessibilidade, dotadas de equipamentos e serviços diversificados, de infraestrutura de boa qualidade e proximidade da oferta de empregos, tornando ociosos os elevados investimentos sociais neles cristalizados.

As condições históricas de desenvolvimento socioeconômico e de provisão da habitação no país resultaram, no ano 2010, no déficit acumulado superior a 6,940 milhões de unidades habitacionais, conforme estimativas da Fundação João Pinheiro (FJP). No estado do Pará e no município de Belém, os déficits estimados alcançavam, respectivamente, 410,799 mil e 72,401 mil unidades habitacionais (FJP, 2013).

Para diminuir esse déficit acumulado e atender à demanda futura por habitação, várias ações 
têm sido empreendidas pelos governos, destacando-se a instituição do Sistema Nacional de Habitação de Interesse Social (SNHIS), a elaboração do Plano Nacional de Habitação (PLANHAB), do Plano Estadual de Habitação de Interesse Social (PEHIS) e do Plano Municipal de Habitação de Interesse Social de Belém (PMHIS). Ademais, tramita, no Congresso Nacional, o Projeto de Lei ${ }^{\circ}$ 6.342/2009 (Brasil, 2009), que institui, no âmbito do SNHIS, o Serviço de Moradia Social para famílias de baixa renda, apoiado na locação como estratégia de provisão de moradia e de promoção social dos beneficiários.

Políticas governamentais instituídas ou propostas pretendem privilegiar grupos mais vulneráveis da população e contemplam, entre outras formas e em alguma medida, a provisão habitacional através de aluguel social. Contudo, até o momento, ainda há poucos avanços na implementação de programas que tenham por base o acesso à moradia digna desvinculado do estatuto da propriedade privada ou da concessão de direito de uso, conforme mostra o estudo desenvolvido por Pasternak e D'Ottaviano (2012).

Em Belém, o déficit habitacional acumulado corresponde a mais de $20 \%$ dos domicílios existentes (FJP, 2013), sendo $54,7 \%$ na faixa de renda mensal de até 3 salários mínimos, inclusive os sem rendimentos. Concomitantemente, há um grande volume de imóveis desocupados ou subutilizados (Belém, 2008). De acordo com o Censo Demográfico do IBGE, havia 55,6 mil domicílios não ocupados em 2010, na capital paraense, o que correspondia a 13,1\% do total de domicílios particulares. Esses fatos, por si próprios, evidenciam a importância de se estudarem possibilidades de política habitacional para atender à demanda de caráter social e proporcionar a redução da ociosidade na ocupação de áreas urbanas, fenômeno que se manifesta de forma particularmente intensa no centro histórico.

O estudo ora apresentado parte do pressuposto de que interessa à parcela da população sem rendimentos e no estrato de renda domiciliar de até 3 SMs mensais, residente no Centro Histórico de Belém (CHB), que hoje contribui para o déficit habitacional, permanecer nessa área. Com base nisso, tem como objetivo geral verificar se a oferta decorrente das hipotética requalificação de imóveis não utilizados e subutilizados e da construção de unidades habitacionais em lotes vazios, localizados nesse centro, seria, em termos quantitativos, suficiente para atender parte significativa dessa demanda.

Assim, não desconhecendo que as poucas experiências empreendidas no país e mesmo o Projeto de Lei em tramitação no Congresso Nacional priorizam a locação social como ação destinada a públicos específicos, o presente trabalho adota a perspectiva defendida pelo deputado federal Paulo Teixeira, segundo a qual a locação social é uma solução adequada para toda a demanda até 5 SMs, na medida em que amplia as formas de acesso à moradia e complementa outras formas de provisão habitacional (Pasternak; D’Ottaviano, 2012).

É de se ressaltar que o estudo ora apresentado não tem a pretensão de comprovar que a utilização dos imóveis ora considerados para fins de quantificação da oferta potencial tem viabilidade política, econômica, administrativa e técnica. Trata-se, ao invés disso, de investigação introdutória, que visa, neste primeiro momento, a verificar se existe fundamento quantitativo para se pensar nessa possibilidade.

Os resultados são apresentados em cinco partes. Inicialmente, analisa-se como a locação social vem sendo tratada em políticas públicas instituídas e propostas, com ênfase nos planos governamentais de habitação de interesse social. Posteriormente, é feita uma caracterização do processo histórico de ocupação do CHB, bem como das propostas existentes no Plano Diretor vigente e no PMHIS. A metodologia utilizada para o cálculo da oferta e da demanda potenciais é exposta na seção seguinte, sendo sequenciada pela apresentação e análise dos resultados encontrados. Por fim, nas considerações finais, são pontuadas as implicações dos resultados obtidos, bem como são indicados veios possíveis de investigação para o aprofundamento do tema. 


\section{LOCAÇÃO SOCIAL EM POLÍTICAS HABITACIONAIS}

A locação social, como integrante da política de habitação de âmbito nacional, tem como marco referencial importante o PLANHAB. Concluído em 2008, esse plano previu a locação social no eixo "Estratégias Urbano-Fundiárias", cujos objetivos gerais são "garantir acesso à terra urbanizada, legalizada e bem localizada para a provisão de HIS (unidades prontas ou lotes)" e "regularizar os assentamentos informais, garantindo a permanência dos moradores de baixa renda" (Brasil, 2010, p.120126). Na Linha Programática que compreende Produção e Aquisição da Habitação, o PLANHAB prevê a "Promoção pública de locação social de unidades habitacionais em centros históricos e áreas urbanas consolidadas", com vistas a:

[...] subsidiar parte dos aluguéis de unidades habitacionais para os Grupos de Atendimento $1 \mathrm{e}$ $2^{1}$ em centros urbanos e áreas urbanas consolidadas de metrópoles e centros regionais localizados nos municípios tipos A, B, C, D e E. ${ }^{2}$ Visa constituir-se numa alternativa de acesso à moradia que permite mobilidade espacial dos beneficiários que necessitam mudar os locais de residência ou que, por sua condição de vulnerabilidade social, não podem se responsabilizar pela propriedade de um imóvel (2010, p. 156).

A referida ação se encontra no contexto de outras previstas no PLANHAB, com destaque para a "Promoção de Unidades Habitacionais Urbanas para Arrendamento" e "Promoção de Unidades Habitacionais em Áreas Urbanas Centrais”. Entretanto, a promoção pública de locação social se di-

\footnotetext{
${ }^{1}$ O Grupo de Atendimento 1 envolve "famílias sem renda ou com renda líquida abaixo da mínima necessária à capacidade de assumir um compromisso de retorno regular e estruturado (abaixo da linha de financiamento)“ e o Grupo de Atendimento 2 se refere a famílias com renda mensal que permite assumir algum compromisso de pagamento (mensal) regular e estruturado e acessar financiamento imobiliário, mas em valor insuficiente para obter uma moradia adequada e, ainda, com alto risco de crédito para os agentes financeiros (e por eles têm sido evitadas), em decorrência de suas rendas informais e reduzidas e das precárias garantias oferecidas para o financiamento“ (Brasil, 2010, p.17).

${ }^{2}$ Integram os tipos A, B, C, D e E os municípios que compõem as regiões metropolitanas e aqueles com mais
} de 100 mil habitantes (2010, p.15) ferencia dessas ações porque lida apenas com o aluguel, enquanto que a promoção para arrendamento admite a opção de compra do imóvel, e a produção de moradia em áreas centrais contempla a aquisição subsidiada de unidades habitacionais (Brasil, 2010, p.151-155).

No âmbito do estado do Pará, a locação social está proposta no PEHIS, ${ }^{3}$ elaborado entre $2008 \mathrm{e}$ 2010, apenas como "solução de atendimento habitacional baseado no aluguel subsidiado pelo poder público, voltada prioritariamente para cidades com alto fluxo migratório e em caso de remanejamento, principalmente aquelas impactadas por grandes projetos." (Pará, 2010, p. 89). Cabe ressaltar que, no momento, o PEHIS está sendo atualizado.

Na esfera do município de Belém, o PMHIS prevê o Programa de Produção de Novas Unidades Habitacionais, com o objetivo de atender a famílias com renda de até $3 \mathrm{SMs}$. Duas prioridades de atendimento são consideradas para o programa: uma destinada à população egressa de domicílios localizados em assentamentos precários e outra relacionada à demanda não vinculada a esse tipo de domicílio. Nessa última, a produção de unidades habitacionais “[...] será exclusiva para famílias que não tenham habitação ou financiamento habitacional e nunca tenham sido contempladas na política habitacional pública”, sendo estabelecidas as seguintes prioridades:

- Tempo de residência em Belém de no mínimo 02 anos;

- Famílias com renda de 0 a 03 salários mínimos;

- Famílias que moram de aluguel e comprometem mais de $30 \%$ de sua renda com aluguel;

- Famílias que moram em situação de coabitação (mais de um núcleo familiar no mesmo domicílio - famílias conviventes) e em situação de adensamento excessivo, em domicílios que tenham mais de 3 moradores por dormitório;

· Famílias chefiadas por mulheres;

- Famílias de que façam parte pessoas com deficiência;

- Famílias cujo sustentáculo seja Idosos Aposentados. (Belém, 2012, p. 76).

${ }^{3}$ Conforme a Minuta de Projeto de Lei para instituir a Política Estadual de Habitação de Interesse Social, aprovada pelo Conselho Estadual das Cidades em 08.03.2010, que acompanha o PEHIS. 
Integrando o programa, estão previstos subprogramas, entre os quais:

Subprograma de Habitação Produzida pelo Mercado, que, especificamente em relação à área central da cidade, tem o objetivo de:

[...] viabilizar a produção de unidades habitacionais de interesse social e de mercado popular a partir da reabilitação de imóveis subutilizados ou vazios na área central de Belém (horizontais e verticais, públicos e privados), considerando-se a disponibilidade de recursos do PMCMV para essa modalidade (2012, p.78).

Subprograma de Locação Social destinado a famílias e pessoas com renda de 0 a 3 SMs, com o seguinte objetivo:

Produzir unidades novas ou adquirir e reformar, se necessário, imóveis já existentes constituindo um parque habitacional público com o intuito de garantir o direito à moradia para um público específico em situação de vulnerabilidade social e/ou em função de impedimento de exercer o direito à moradia, seja em função da ação direta da PMB ou em função de situações de risco iminente ou calamidade pública. O benefício se dá a partir do subsídio dado pelo poder público municipal sobre o valor do aluguel do imóvel disponibilizado pelo subprograma, sem que se torne proprietário do mesmo. Os valores arrecadados com os aluguéis deverão retornar para o Fundo Municipal de Habitação de Interesse Social (Belém, 2012, p. 79).

As prioridades estabelecidas para atendimento por este subprograma são:

\section{- Pessoas acima de 60 anos.}

- Pessoas em situação de rua, abrangendo aquelas que se encontram em albergues, abrigos, alojamentos provisórios, hotéis, pensões e moradias transitórias.

- Pessoas com deficiência.

- Moradores em áreas de risco e de insalubridade que precisem ser removidos, compreendendo pessoas provenientes de assentamentos precários e aquelas que estão sendo atendidas pelo Auxílio Moradia.

O Projeto de Lei n ${ }^{0}$ 6.342/2009 também contempla a locação social como instrumento para garantir moradia digna para população de baixa renda. O serviço de moradia social proposto visa a “[...] garantir a moradia digna para população de baixa renda, por meio de um conjunto de ações e iniciativas integradas com as demais políticas de desenvolvimento urbano e promoção social”. Tal serviço tem ainda como objetivos: "[...] II - utilização do estoque imobiliário ocioso e da infraestrutura instalada e III - preservação e recuperação do patrimônio cultural” (Brasil, 2009).

No tocante ao público-alvo, o Projeto de Lei propõe:

I. Pessoas com 60 anos ou mais;

II. Pessoas em situação de rua;

III. Pessoas com deficiência;

IV. Famílias e indivíduos em situação de vulnerabilidade ou risco social e pessoal [...];

V. Moradores de áreas de risco, insalubridade e de preservação ambiental (2009, p. 2-3)

Um aspecto relevante dessa iniciativa parlamentar reside na previsão de duas modalidades de oferta de unidades para locação social, denominadas de parque público e parque privado. A primeira é constituída por "[...] unidades habitacionais novas ou requalificadas, de propriedade de pessoa jurídica de direito público, produzidas ou adquiridas de terceiros." (Brasil, 2009, p.3). A segunda é composta por "[...] unidades habitacionais novas ou requalificadas, de propriedade de pessoa física ou jurídica de direito privado, alugadas para o poder público para os fins deste serviço" (2009, p. 3).

Das experiências com aluguel social, destaca-se o Programa de Locação Social aprovado em 2002 pelo Conselho do Fundo Municipal de Habitação do Município de São Paulo, parcialmente implementado. Nesse programa, locação social é entendida como:

[...] a política destinada a produzir unidades habitacionais de aluguel compatíveis com as necessidades familiares e com a capacidade de pagamento das famílias de baixa renda. Embora seja a solução básica de todas as políticas habitacionais européias [sic], os sistemas baseados em locação não conseguiram até hoje ser discutidos no Brasil, face à predominância absoluta do modelo e do sonho da casa própria. No programa habitacional de São Paulo, a Locação Social será complementar a uma política de casa própria, procurando atingir famílias sem condições 
Simaia do Socorro Sales das Mercês,

Helena Lúcia Zagury Tourinho,

Marco Aurélio Arbage Lobo

financeiras para a aquisição ou que tenham o aluguel como opção, permanente ou ocasional (São Paulo, 2002, p. 6).

Os critérios para produção e seleção das unidades habitacionais adotados no referido programa são:

1. As unidades para utilização no programa de locação social poderão ser produzidas a partir de construção de novas edificações ou através da aquisição e reforma, se necessária, de imóveis existentes.

2. Entre as áreas para produção de novas unidades e imóveis passíveis de seleção, a definição de prioridade deve ser feita a partir dos seguintes critérios:

a. maior ou plena utilização de investimentos já realizados;

b. menor investimento por família ou pessoa;

c. maiores opções de acesso a transporte coletivo; d. região que concentre maiores índices de emprego (2002, p. 2).

Do exposto, é possível inferir que a locação social tem sido contemplada em políticas públicas, assim como em planos nacionais, estaduais e municipais de habitação existentes no país, sendo voltada, sobretudo, para o atendimento de segmentos de renda de até três salários mínimos. Nota-se, também, que se apresenta como uma possibilidade para redução da ociosidade do estoque imobiliário.

É nesse contexto que se enfocará a análise

Figura 1 - Belém - PA: Localização

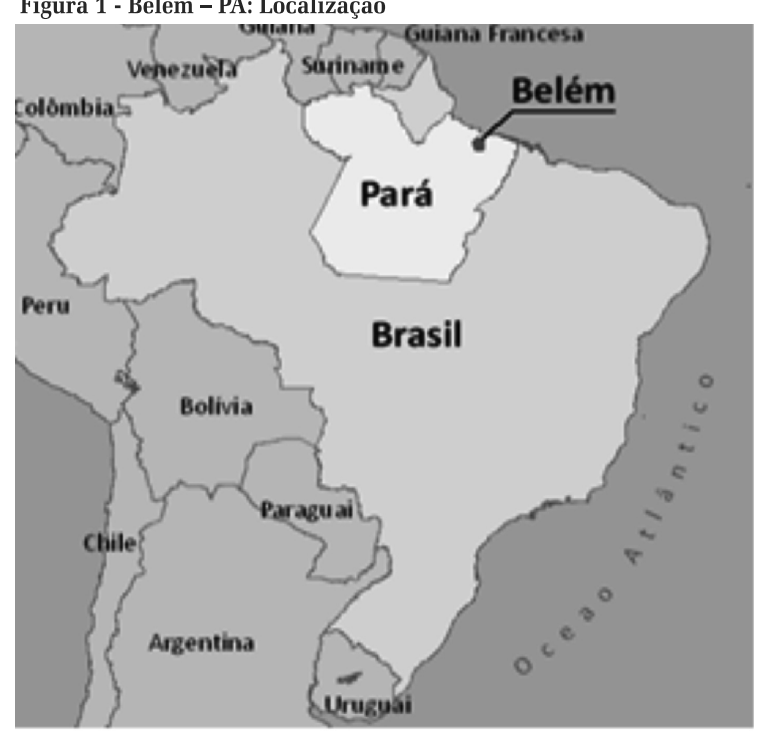

Fonte: Elaboração: Luis Henrique Rocha Guimarães sobre a possibilidade de utilização dessa modalidade de acesso à moradia digna no CHB.

\section{CENTRO HISTÓRICO DE BELÉM: característi- cas e propostas}

O CHB está localizado na parte sudoeste da área urbana e engloba parte do bairro da Cidade Velha e a totalidade do bairro da Campina, no município de Belém, estado do Pará (Figuras 1 e 2).

Teve sua ocupação iniciada nas primeiras décadas do século XVII, quando, para controlar a foz do rio Amazonas, garantir as conquistas territoriais e impedir a ocupação pelos invasores ingleses, franceses e holandeses, a Coroa Portuguesa enviou, para a região, Francisco Caldeira Castelo Branco, que fundou um forte na confluência do Rio Guamá com a Baía de Guajará.

Até a década de 1950, o centro histórico era o principal núcleo de atividades terciárias da cidade. Nele estavam concentrados os prédios que abrigavam as funções políticas e administrativas, as atividades portuárias, o comércio varejista de produtos sofisticados e populares. Para ele convergiam todas as vias principais e os transportes coletivos urbanos.

A partir dos anos 1960, Penteado (1968) já constata processos de descentralização de algumas atividades voltadas para as camadas de alta renda.

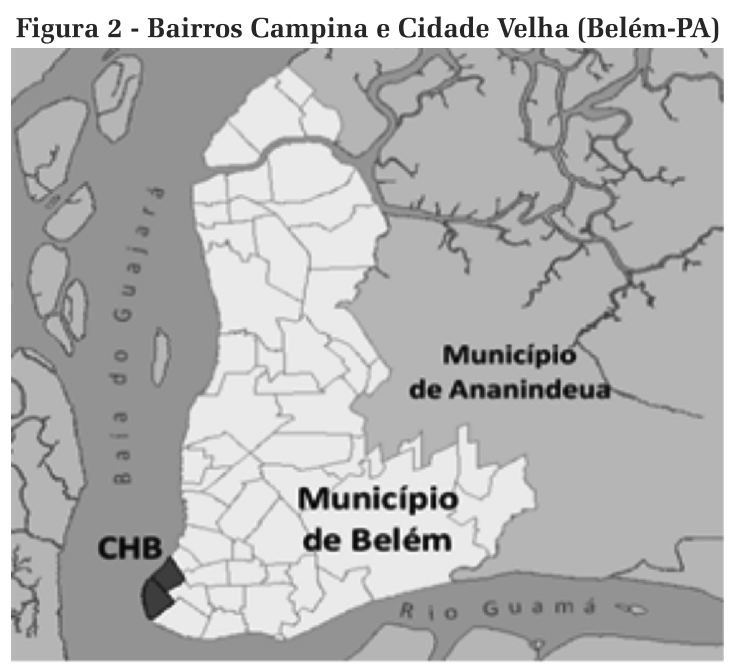

Fonte: Elaboração: Luis Henrique Rocha Guimarães 
Nos anos 1970 e nas décadas seguintes, esse processo se intensifica, e o centro começa a passar por transformações nas suas funções. A emergência de shopping centers fora do núcleo terciário original, assim como de condomínios fechados e conjuntos habitacionais nas áreas de expansão urbana, além dos problemas de acessibilidade e de mobilidade urbana, certamente colaboraram para a consolidação das transformações operadas no CHB, que passa, cada vez mais, a se especializar em algumas atividades e a se voltar para um comércio destinado às camadas populares. Parte das atividades administrativas, da mesma maneira, também vem se deslocando para outras áreas da cidade, quer seguindo uma estratégia de descentralização para melhor atender à população, quer fugindo dos congestionamentos e problemas de estacionamento na área central.

Nesse processo, vários imóveis foram abandonados e permanecem desocupados. Alguns entraram em processo de degradação física, estando, hoje, em situação de ruínas; outros foram desmembrados para abrigar pequenas atividades. Antigas residências, impossibilitadas de modificação pelo estatuto do tombamento, cederam lugar a estabelecimentos comerciais de baixo padrão, ou se tornaram espaço de guarda de mercadorias e mobiliários usados por ambulantes. Algumas, após serem derrubadas, tiveram seu espaço utilizado como estacionamento.

De acordo com o Plano Diretor do Município de Belém (PDM), aprovado em 2008, o CHB integra a Zona de Ambiente Urbano 7 (ZAU 7), estando, na sua quase totalidade, no Setor I, que se caracteriza, conforme o Art. 94:

[...] por seus atributos históricos, paisagísticos e culturais, por desempenhar tradicionalmente as funções de centro comercial, administrativo, de serviços e portuário, com atendimento a todo o Município, e por apresentar:

I - infraestrutura consolidada;

II - mobilidade reduzida;

III - degradação paisagística e ambiental;

IV - edificações históricas descaracterizadas;

$\mathrm{V}$ - grande número de imóveis desocupados e subutilizados (Belém, 2008, p. 58).
Informações do banco de dados da pesquisa nacional Mercado Imobiliário em Centros Históricos, cujo módulo de Belém é desenvolvido pela Universidade da Amazônia, mostram que, em 1997, ${ }^{4}$ havia 1.652 lotes com uso exclusivo habitacional. Em 2013, essa quantidade já era de 1.518 unidades. ${ }^{5}$ Essas mesmas fontes mostram o crescimento bastante expressivo na quantidade de imóveis desocupados e em ruínas. Ao se considerar que alguns imóveis se acham apenas parcialmente ocupados, a taxa de ociosidade dos imóveis no CHB é ainda maior.

O grau de ociosidade imobiliária também pode ser avaliado a partir dos dados do Censo Demográfico de 2010, que registra 982 domicílios não ocupados no conjunto formado pelos bairros da Campina e Cidade Velha, sendo 580 no primeiro e 402 no segundo. Em termos percentuais, esses valores correspondem, respectivamente, a 19\%, $13 \%$ e $27,9 \%$ do total de domicílios dessas unidades territoriais. Destaca-se, portanto, o elevado quantitativo de moradias ociosas, especialmente no bairro da Campina.

Com uma área de $1.731 .495 \mathrm{~km}^{2}$, os dois bairros que integram o CHB, segundo Censo Demográfico do IBGE, em 2010, contavam com 5.151 domicílios (IBGE, 2010), sendo que 1.708 unidades imobiliárias são de valor histórico (Belém, 2004). No período 2000-2010, conforme a mesma fonte, nota-se redução na taxa de crescimento dos domicílios do CHB e na sua participação em relação ao total de domicílios do município.

Em termos populacionais, em 2010, conforme dados do Censo do IBGE, 18.284 pessoas moravam $\mathrm{CHB}$, representando um crescimento de $4,9 \%$ em relação a 2000 , muito inferior ao crescimento demográfico municipal, que, nessa mesma década, foi de $8,8 \%$.

${ }^{4}$ Conforme dados do Cadastro Técnico Multifinalitário, publicado em 1998 pela Companhia de Desenvolvimento da Área Metropolitana de Belém.

${ }^{5}$ Segundo levantamento de campo de uso e ocupação do solo realizada pela equipe da pesquisa "Mercado Imobiliário em Centros Históricos das Cidades Brasileiras Módulo de Belém”, financiada pelo Conselho Nacional de Desenvolvimento Científico e Tecnológico (CNPq) e pela Fundação Instituto para o Desenvolvimento da Amazônia (FIDESA). 
Simaia do Socorro Sales das Mercês,

Helena Lúcia Zagury Tourinho,

Marco Aurélio Arbage Lobo

Quanto ao rendimento mensal domiciliar, em 2010, o percentual de domicílios com rendimento de até 3 SMs representava $28,8 \%$ do total, aí incluídos os sem rendimentos, enquanto aqueles com mais de 20 SMs totalizaram 10,4\%.

Quanto à condição de ocupação, a participação dos domicílios alugados cresceu de 27,4\% para 32,6\%, no período 2000-2010, ao mesmo tempo em que caiu a participação dos domicílios próprios (de 68,6\% para 63,7\%), dos cedidos (3,5\% para $3,3 \%$ ) e daqueles agrupados na categoria "outros" (de $0,5 \%$ para $0,3 \%$ ).

Esses dados e os anteriormente citados revelam, claramente, o baixo dinamismo demográfico dessa área. Mostram ainda que o processo de gentrificação, tão propalado na literatura acadêmica, aqui não se fez notar, mesmo com os maciços investimentos que foram feitos nessa área da cidade, sobretudo a partir dos anos 1990, em projetos de reforma do complexo Ver-o-Peso, de requalificação portuária do complexo de lazer Estação das Docas, de recuperação e restauro de vários imóveis públicos e privados por meio do Programa Monumenta (projeto Feliz Lusitânia), dentre outros. Mas, acima de tudo, deixam indícios claros de que o mercado imobiliário, no tocante ao uso habitacional, no CHB, vem se caracterizando, sobretudo, pela crescente participação da modalidade aluguel.

Se se adicionar à análise a enorme ociosidade de imóveis (integral ou parcial) existente no CHB, é lícito pensar o aluguel social como instrumento capaz de promover, para segmentos de menor renda, moradia digna e bem localizada, em área com infraestrutura, acessibilidade e oferta de emprego.

Mas como os documentos de política urbana e o planejamento habitacional municipal vêm tratando essa possibilidade?

O PDM, no Art. 26, estabelece entre os objetivos da política de habitação:

[...] I - reduzir o déficit habitacional do Município;

[...] III - priorizar a permanência das famílias em área objeto de intervenções urbanas ou em áreas próximas às mesmas;
[...] IX - promover a otimização das redes de infraestrutura urbana (Belém, 2008, p. 17-18).

As diretrizes dessa política são apontadas no Art. 27, de onde se destacam as de:

[...] II - estimular a utilização dos vazios urbanos, inserindo-os no âmbito de uma política habitacional de interesse social;

[...] XIV - promover a ocupação das edificações desocupadas ou subutilizadas, em especial as existentes no Centro Histórico de Belém (Belém, 2008, p. 18-19).

O PDM classifica o CHB, no zoneamento especial, como Zona Especial de Preservação do Patrimônio Histórico e Cultural (ZEIP) e, no zoneamento ordinário, como Zona de Ambiente Urbano 7 (ZAU 7). A requalificação e reabilitação aparecem, no Art. 113, como diretrizes do PDM para a ZEIP onde se acha o CHB. Da mesma maneira, são indicadas como diretrizes da ZAU 7 Setor I, de interesse para este trabalho: "I - reabilitar o núcleo histórico e II - promover programas habitacionais" (Belém, 2008, p. 58).

Como se pode constatar, o PDM, embora não contemple a possibilidade de uso do aluguel social, foi sensível à necessidade de fazer com que os imóveis subtilizados e desocupados cumpram sua função social e reconheceu a importância de desenvolver programas habitacionais nessa área da cidade.

No caso doPMHIS, consta, entre suas diretrizes:

XIII - Promover a utilização edificações verticais desocupadas ou subutilizadas existentes no Centro Histórico de Belém e seu entorno, bem como de conjuntos habitacionais degradados para habitação de interesse social com vistas a garantir o melhor aproveitamento da infraestrutura instalada, dos equipamentos urbanos e do patrimônio construído (Belém, 2012, p. 69).

De interesse para este trabalho, uma ação estratégica prevista no PMHIS, no âmbito do programa Produção e Melhoria de Habitação, é relevante:

Buscar a viabilização do programa Minha Casa Minha Vida para a faixa de 0 a 03 salários mínimos, incluindo a modalidade de reabilitação de imóveis em áreas centrais para a produção de HIS e Habitação de Mercado Popular (HMP) (p. 77). 
Como se pode constatar, nem o plano diretor nem o plano de habitação de interesse social previram, explicitamente, a locação social no CHB, mesmo que ambos tenham reconhecido a ocorrência de imóveis desocupados e subutilizados nesse espaço.

Diante dessa omissão, a questão que emerge, então, é saber se haveria demanda e (ou) oferta para esse tipo de modalidade de habitação de interesse social no CHB.

\section{METODOLOGIA DE CÁLCULO DE OFERTAE DEMANDA POTENCIAIS DE IMÓVEIS PARA LOCAÇÃO SOCIAL NO CHB}

A estimativa da oferta potencial para aluguel social no CHB foi realizada com base no Sistema de Informações Geográficas (SIG) da pesquisa "Mercado Imobiliário em Centros Históricos de Cidades Brasileiras", coordenada pela Universidade Federal de Pernambuco, cujo módulo de Belém é desenvolvido pela Universidade da Amazônia.

Para isso, como ponto de partida, foram tomadas as informações contidas na camada do SIG composta pelo mapa vetorial, com a representação dos lotes do CHB e seus atributos alfanuméricos, como uso do solo, número de pavimentos (em caso de lote edificado), estado de conservação, ocupação dos pavimentos (em edificações até quatro pavimentos) e área dos lotes, dentre outros. As informações relativas às camadas foram atualizadas por meio de pesquisa de campo realizada nos meses de abril e maio de 2013.

Foram consideradas, como oferta potencial para aluguel social, as edificações de até quatro pavimentos, total ou parcialmente desocupadas, as edificações em ruínas e os terrenos vazios existentes no CHB. Entende-se que, no caso das duas primeiras, o aluguel social pode ser viabilizado com o uso dos imóveis, para o que podem ser necessárias reformas e (ou) adaptações, de maneira a comportar uma ou mais unidades habitacionais. A exclusão das edificações existentes com mais de quatro pavimentos justifica-se pelo fato de que, nesses casos, tornar-se-ia necessário instalar elevador, o que onera significativamente as despesas de condomínio e pode inviabilizar a moradia do público-alvo do aluguel social. Quanto aos imóveis em ruínas e terrenos vazios, a viabilização do aluguel social poderia ser alcançada com a construção de novas unidades habitacionais.

O primeiro passo para a quantificação da oferta potencial para aluguel social foi extrair, do SIG, a área dos lotes nas quatro categorias de imóveis (total ou parcialmente desocupados, em ruínas e terrenos vazios) e, naqueles total ou parcialmente desocupados, o número de pavimentos sem ocupação. Em seguida, foi calculado o número de unidades habitacionais com potencial para serem ofertadas, em dois grupos:

a) No grupo dos imóveis total ou parcialmente desocupados, aqui considerados como oferta potencial para aluguel social mediante a adaptação das edificações, multiplicou-se a área dos lote pelo número de pavimentos ociosos e, em seguida, por um coeficiente de área útil, definido como a estimativa da parcela da área total de cada edificação que poderá ser efetivamente utilizada para uso habitacional. O valor que se adotou para esse coeficiente tomou por base a experiência de implantação do Projeto Piloto de Habitação de Interesse Social do Centro Histórico de São Luís, ${ }^{6}$ sendo esse valor resultante da soma da área útil dos apartamentos $\left(40 \mathrm{~m}^{2} \times 18\right.$ apartamentos $=720 \mathrm{~m}^{2}$ ) dividida pela área total da edificação $\left(966 \mathrm{~m}^{2}\right)$, arredondado para uma casa decimal, totalizando 0,7. O cálculo foi concluído com a divisão do resultado da operação anterior pela área média arbitrada de $60 \mathrm{~m}^{2}$ para cada unidade habitacional.

b) No grupo dos terrenos vazios e edificações em ruínas, aqui considerado como oferta potencial para aluguel social mediante a produção de novas edificações, multiplicou-se a área do lote pelo menor coeficiente de aproveitamento previsto para o CHB, ou seja, de 0,6. O valor encontrado foi mul-

${ }^{6}$ Esse projeto foi concretizado através de uma parceria entre a Prefeitura de São Luís, o Ministério das Cidades e o Governo Espanhol, através da Junta Andalucia (Prefeitura..., 2011). 
Simaia do Socorro Sales das Mercês,

Helena Lúcia Zagury Tourinho,

Marco Aurélio Arbage Lobo

tiplicado pelo coeficiente de área útil anteriormente explicitado $(0,7)$ e dividido pela área média arbitrada para cada unidade habitacional $\left(60 \mathrm{~m}^{2}\right)$.

O cálculo da demanda por aluguel social no CHB foi baseado na metodologia desenvolvida pela FJP (2013) para estimar o déficit habitacional. Assim, este trabalho considerou, como potenciais beneficiários de programas de locação social, os moradores de domicílios improvisados, rústicos, cômodos, alugados com adensamento excessivo e (ou) que combinam rendimento domiciliar até 3 SMs com valor do aluguel igual ou superior a $30 \%$ desse rendimento. Também foram admitidos como potenciais demandantes as famílias conviventes secundárias com desejo de formar um domicílio próprio. As informações necessárias foram obtidas nos microdados da amostra do Censo Demográfico 2010 (IBGE, 2010b) disponíveis para a área de ponderação denominada "Centro Histórico”, que abrange a área definida pela Lei n. 7.709/ 1994 e áreas vizinhas (Figura 3). O tratamento dos dados foi feito com o pacote estatístico R.

Os dados de domicílios improvisados, rústicos e cômodos foram obtidos diretamente da

Figura 3 - Área de ponderação Centro Histórico e limites do

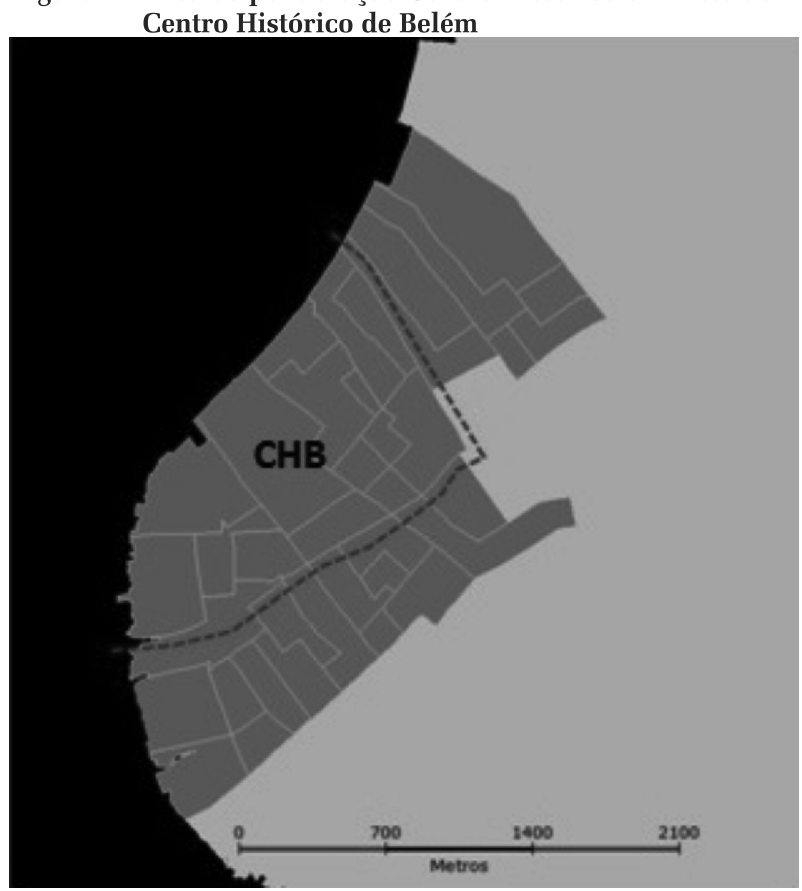

Fonte: Autores, com base em IBGE (2010b) e Belém (1994) amostra, multiplicando o número de casos por seus respectivos pesos, conforme informação dos microdados do IBGE. Alocaram-se os domicílios nos componentes da demanda habitacional considerando se atendiam, pelo menos, a um dos seguintes critérios:

a) Domicílios improvisados: "V4001 - Espécie", classe "05 - Domicílio particular improvisado ocupado";

b) Domicílios rústicos: "V0202 - Material predominante, paredes externas", classes " 5 - Taipa não revestida”; "6 - Madeira aproveitada”; "7 Palha: para paredes feitas de sapé, folha ou casca de vegetal, etc."; "8 - Outro material"; e "9 Sem parede";

c) Cômodos: "V4002 - Tipo de espécie", classe "14 - Habitação em: casa de cômodos, cortiço ou cabeça de porco";

d) Aluguel excessivo: combinação de duas situações:

d.1) "V6530 - Rendimento domiciliar, salários mínimos, em julho de 2010” com valor entre 0 (zero) e 3 (três);

d.2) "V2012 - Aluguel em número de salários mínimos" com valor maior que 0 (zero) e 3 (três) vezes ou mais maior do que o valor registrado na variável V6530.

e) Densidade domiciliar excessiva: "V6204 Densidade morador/dormitório" com valor superior a 3 (três).

f) Famílias conviventes: combinação de dois critérios:

f.1) Variável "V5020 - Número da Família” com valor entre 2 (dois) e 9 (nove);

f.2) Multiplicação do número de famílias que atenderam ao critério anterior pela média dos coeficientes de famílias conviventes, residentes na Região Metropolitana de Belém, que foram enquadradas como "2 -Sim" na variável "V0410 - Intenção de se mudar e constituir outro domicílio" da Pesquisa Nacional por Amostra de Domicílios (PNAD) dos anos 2009 e 2011.

Nos casos em que um determinado domicílio se enquadrou em mais de um dos itens "b" a "e" antes relacionados, ele foi computa- 
do apenas no que estivesse primeiramente mencionado na listagem apresentada. ${ }^{7}$

\section{DEMANDA E OFERTA POTENCIAIS DE LOCA- ÇÃO SOCIAL NO CENTRO HISTÓRICO DE BELÉM}

A demanda potencial por domicílios para aluguel social no CHB e áreas vizinhas (Tabela 1), correspondente ao quantitativo do déficit habitacional, estava concentrada em dois componentes, que responderam por $84 \%$ do total: as famílias conviventes com intenção de formar um novo domicílio e os domicílios com ônus excessivo de aluguel. No primeiro caso, o resultado pode expressar, dentre outras situações, a incapacidade de as famílias desse segmento de renda arcarem isoladamente com os custos de moradia exclusiva no $\mathrm{CHB}$, face aos preços vigentes no mercado de aluguel. O elevado

Tabela 1 - Área de Ponderação Centro Histórico: déficit habitacional por componentes, 2010

\begin{tabular}{|c|c|c|}
\hline Componente & Quantidade de domicílios & $(\%)$ \\
\hline Domicílios improvisados & 19 & 1,3 \\
\hline Domicílios rústicos & 0 & 0,0 \\
\hline Domicílios em cômodos & 20 & 1,4 \\
\hline $\begin{array}{l}\text { Domicílios com ônus } \\
\text { excessivo de aluguel }\end{array}$ & 601 & 41,2 \\
\hline $\begin{array}{l}\text { Domicílios alugados com } \\
\text { densidade demográfica } \\
\text { excessiva }\end{array}$ & 194 & 13,3 \\
\hline $\begin{array}{l}\text { Famílias conviventes com } \\
\text { intenção de formar um } \\
\text { novo domicílio }\end{array}$ & 623 & 42,8 \\
\hline Total & 1.457 & 100,0 \\
\hline
\end{tabular}

os com ônus excessivo de aluguel no déficit. Ressalte-se que, se o desempenho desse indicador, de um lado, revela a dificuldade no pagamento de aluguéis, por outro lado, permite supor que parte expressiva dos moradores de baixa renda do $\mathrm{CHB}$ aceitaria, em tese, usar a modalidade do aluguel social para atender à sua necessidade de moradia digna.

Com uma participação bem mais modesta que os dois componentes anteriores, os domicílios alugados com densidade demográfica excessiva reforçam a hipótese de impossibilidade do acesso das famílias de baixa renda a moradias nas condições do mercado de aluguel presentes no CHB e, em especial, em dimensões adequadas às suas necessidades.

Os domicílios improvisados aparecem em número bastante reduzido, e não há registro de domicílios rústicos, o que pode ser explicado pelo fato de a maior parte do CHB e seu entorno constituírem área consolidada e densamente construída, restando pouco espaço livre para ocupações dessa natureza.

Em relação à oferta potencial (Tabela 2), a estimativa dos componentes considerados neste trabalho revela que é na adaptação de edificações que se acha a maior possibilidade de atender à demanda potencial das camadas de menor renda, o que é facilmente justificado pelas características de ocupação do CHB. As possibilidades oferecidas por esse componente são tão expressivas que podem, sozinhas, responder com folga, à demanda potencial identificada no Centro, ou seja, se explorada, poderia mesmo vir a contribuir, também, para a redução do déficit de moradias hoje localizado em outras áreas da cidade. nível dos preços praticados nesse mercado em relação à capacidade de pagamento do segmento de renda de até 3 SMs explica, também, a expressiva participação dos domicíli-

7 “Os componentes são calculados de forma sequencial, na qual a verificação de um critério está condicionada à não ocorrência dos critérios anteriores. A forma de cálculo garante que não

há dupla contagem de domicílios, exceto pela coexistência de algum dos critérios e uma ou mais famílias conviventes secundárias." (FJP, 2013, p.14).
Tabela 2 - Área de Ponderação Centro Histórico: Oferta potencial por componentes, 2013

\begin{tabular}{|c|c|c|}
\hline Componente & \begin{tabular}{|c|} 
Quantidade de \\
unidades habitacionais
\end{tabular} & (\%) \\
\hline $\begin{array}{l}\text { Adaptação de edificações até } 4 \\
\text { pavimentos total ou parcialmente } \\
\text { desocupadas }\end{array}$ & 2.547 & 91,2 \\
\hline $\begin{array}{l}\text { Produção habitacional em } \\
\text { lotes ocupados por edificações em } \\
\text { ruínas e vazios }\end{array}$ & 245 & 8,8 \\
\hline Total & 2.792 & 100,0 \\
\hline
\end{tabular}


Simaia do Socorro Sales das Mercês,

Helena Lúcia Zagury Tourinho,

Marco Aurélio Arbage Lobo

\section{CONSIDERAÇÕES FINAIS}

Ao identificar e quantificar a oferta e a demanda potencial por aluguel social no CHB, o presente estudo revelou que, hipoteticamente, é possível pensar na utilização dessa modalidade como uma alternativa não só para responder às necessidades habitacionais de baixa renda instaladas nessa área da cidade, como também para colaborar na redução do déficit em outras áreas urbanas. O componente que apresentou a maior potencialidade de contribuição, nesse sentido, foi o referente aos imóveis desocupados e subutilizados, ou seja, é na adaptação de edificações que pode estar o papel mais importante do CHB na redução do problema da oferta insuficiente da moradia digna, papel que não tem sido reconhecido nas políticas habitacionais. Aliás, a hipótese de utilização do aluguel social em centros históricos não foi devidamente contemplada no PEHIS e no PMHIS.

É mister ressaltar que a concretização da oferta potencial está sujeita à superação de um conjunto de obstáculos, tanto gerais, relativos a qualquer política de locação social, como específicos, referentes à aplicação desse tipo de política em centros históricos.

Quanto à primeira, cabe recuperar os aspectos apontados por Pasternak e D'Ottaviano (2012), ou seja, a necessidade de: i) superar a ideologia dominante que valoriza a propriedade privada em detrimento do aluguel social; ii) capacitar o poder público para a gerência da política; iii) criar mecanismos para envolver a iniciativa privada; iv) encontrar fontes de financiamento para implementar a política, envolvendo, dentre outros, a formação do estoque público e (ou) privado de unidades habitacionais destinadas ao aluguel social e os subsídios para o pagamento dos aluguéis.

No que tange às dificuldades adicionais, decorrentes da condição específica que assume o aluguel social em centros históricos, vale destacar: i) os limites impostos à adaptação das edificações pela legislação de tombamento; ii) os requisitos técnico-construtivos implicados na requalificação de edificações antigas; iii) os custos elevados de recuperação, adaptação e manutenção de prédios antigos; iv) o preço da terra para a aquisição de lotes destinados à produção.

Diante desse quadro, e considerando o caráter introdutório do presente trabalho, torna-se de fundamental importância a realização de estudos com vistas ao aprofundamento do tema, notadamente aqueles que analisem a viabilidade técnica e econômica de implementação da hipótese aqui formulada. Tais estudos não podem perder de vista que o aluguel social em centros históricos, além de ser uma política de provisão de moradia, configura, também, uma política de conservação do patrimônio histórico e cultural, o que justificaria não apenas a inserção de custos adicionais que eventualmente essa política possa vir a ter, mas ainda os benefícios que dela podem advir para a preservação da memória da cidade.

Recebido para publicação em 02 de dezembro de 2013 Aceito em 02 de março de 2014

\section{REFERÊNCIAS}

BELÉM. Lei n. 8655 de 30 de julho de 2008. Dispõe sobre o Plano Diretor do Município de Belém e dá outras providências Diário Oficial [do Município], n 11.214 , de 5 de setembro de 2008, $2^{\circ}$ Caderno. Disponível em: http:// ww 3 , belem pa.gov, br/www/wp-content/uploads/ Lei_N8655-08_Plano-Diretor.pdf. Acesso em: 3 mar. 2014. . Prefeitura Municipal. Plano Municipal de Habitação de Interesse Social. Belém: 2012.

Plano de Desenvolvimento Local Sustentável do Centro Histórico de Belém. Belém: 2004.

BRASIL. Ministério das Cidades. Plano Nacional de Habitação: Versão para debates. Brasília: 2010. Disponível em: http://www.sst.sc.gov.br/arquivos/id submenu/230/ publiicacao_planhab_capa.pdf. Acesso em: 28 fev. 2014.

BRASIL. Câmara dos Deputados. Projeto de Lei $n^{\circ}$ 6.342/ 2009. Institui no âmbito do SNHIS, o Serviço de Moradia Social para famílias de baixa renda. Brasília, 2009. Disponível em: http://www.camara.gov.br/proposicoesWeb/ prop_mostrarintegra;jsessionid =602267B963FBE7019872A435 DA49 2 DB3.node1 ?codteor $=714254$ \&filename $=$ Avulso + PL +6342/2009. Acesso em: 8 fev. 2014.

FJP. Fundação João Pinheiro. Centro de Estatística e Informacões. Déficit habitacional municipal no Brasil. Belo Horizonte, 2013. Disponível em: http://www.fjp.mg.gov.br/ index. php/docman/cei/deficit-habitacional/216-deficithabitacional-municipal-no-brasil-2010/file. Acesso em: 16 fev. 2014.

IBGE. Instituto Brasileiro de Geografia e Estatística. Censo demográfico 2010a: microdados da amostra - Pará. Rio de Janeiro, 2010a. Disponível em: http://servicodados.ibge.gov.br/ 
Download/Download.ashx? $\mathrm{u}=\mathrm{ftp}$.ibge.gov.br/Censos/ Censo_Demografico_2010/Resultados_Gerais da Amostra/ Microdados/PA.zip. Acesso em: 20 fev. 2014.

IBGE. Instituto Brasileiro de Geografia e Estatística. Censo demográfico 2010b: microdados da amostra - Pará. Rio de Janeiro, 2010b. Disponível em: http://servicodados.ibge.gov.br/ Download/Download.ashx?u=geoftp.ibge.gov.br/ malhas digitais/censo 2010/areas de ponderacao/ 15_PA_Para.zip. Acesso em: 22 fev. 2010.

PARÁ. Plano Estadual de Habitação de Interesse Social. Belém: COHAB, 2010

PASTERNAK, Suzana; D’OTTAVIANO, Camila. (Org. Relatório final: investigacão sobre moradia de aluguel no Brasil. São Paulo: FAUUSP, 2012.
PENTEADO, Antônio Rocha. Belém: estudo de geografia urbana. Belém: EDUFPA, 1968.

PREFEITURA de São Luís entrega primeiros apartamentos do Projeto de Habitação do Centro Histórico. Bastidores 3, São Luís, 3 nov. 2011. Disponível em: http://www. bastidores3.com/2011/11/prefeitura-de-sao-luisentrega.html. Acesso em 12 mar. 2014.

SÃO PAULO. Conselho do Fundo Municipal de Habitação. Resolução CFMH n ${ }^{\circ}$ 23, de 12 de junho de 2002. Aprova o Programa de Locação Social no Município de São Paulo, 2012. Disponível em: http://www.prefeitura.sp.gov.br/cidade/secretarias/upload/RESOLUCAO CFMH23_1252610964.pdf. Acesso em 8 fev. 2014. 
Simaia do Socorro Sales das Mercês,

Helena Lúcia Zagury Tourinho,

Marco Aurélio Arbage Lobo

\section{SOCIAL RENT IN THE HISTORICAL CENTER OF BELÉM: an introductory investigation}

\author{
Simaia do Socorro Sales das Mercês \\ Helena Lúcia Zagury Tourinho \\ Marco Aurélio Arbaje Lobo
}

This article seeks to begin a discussion on the possibility of using social rent as a way of providing decent housing in Belém's Historical Center. To this end, the article: i) analyzes social rent in Brazilian housing policies; ii) identifies and quantifies, for the Historical Center, the potential demand arising from the housing deficit, as well as potential supply, the latter based on the hypotheses of adapting vacant, underused properties, as well as building housing units in lots either vacant or containing ruins. The study concludes, initially, that there is enough supply to meet the demand in the Historical Center and other areas of the city. Finally, it notes that besides being a housing policy, social rent in historical centers is a conservation policy for the historical and cultural heritage, which adds benefits to be accounted for as the result of a proposed policy.

KEYwORDS: Housing policy. Social Rent. Historical Center of Belém.
LOCATION SOCIALE DANS LE CENTRE HISTORIQUE DE BÉLEM: investigation initiale

\author{
Simaia do Socorro Sales das Mercês \\ Helena Lúcia Zagury Tourinho \\ Marco Aurélio Arbaje Lobo
}

Dans cet article nous essayons de lancer la discussion concernant la possibilité d'utiliser la location sociale comme moyen de fournir un logement décent dans le Centre Historique de Bélem. Pour ce faire: i) nous analysons la location sociale dans les politiques brésiliennes du logement; ii) nous identifions et quantifions, pour le Centre, les demandes en potentiel découlant du déficit des logements et l'offre en potentiel à partir des hypothèses d'adaptation des immeubles inoccupés et sous-utilisés ainsi que la construction de logements sur des terrains vacants et sur des terrains avec des ruines. Cette étude en arrive à la conclusion qu'il y a, en principe, une offre capable de répondre à la demande du Centre et d'autres quartiers de la ville. Toutefois on fait remarquer qu'il faut surmonter de nombreux obstacles pour que cette offre existe vraiment. Enfin il faut savoir que les logements sociaux dans les centres historiques supposent non seulement des politiques d'offre de logements, mais aussi l'adoption d'une politique de conservation du patrimoine historique et culturel, ce qui est un avantage qui doit être pris en considération dans les résultats de la politique proposée.

Mots-Clés: Politique des logements. Location sociale. Centre historique de Bélem.

\footnotetext{
Simaia do Socorro Sales das Mercês - Doutora em Arquitetura e Urbanismo. Especialista em Planejamento e Administração de Transporte Urbano pela Universidade Federal do Pará (UFPa), Brasil. Professora do Núcleo de Altos Estudos Amazônicos (NAEA) da UFPa. Tem experiência técnica e acadêmica nas áreas de Arquitetura e Urbanismo, Planejamento Urbano e Regional e Planejamento de Transporte, com ênfase em gestão urbana e políticas públicas, atuando principalmente nos seguintes temas: produção do espaço urbano, habitação, mercado imobiliário; atores sociais; desigualdades socioespaciais; planejamento urbano e transporte urbano.

Helena Lúcia Zagury Tourinho - Doutora em Desenvolvimento Urbano. Professora e pesquisadora do Programa de Mestrado em Desenvolvimento e Meio Ambiente Urbano e do curso de graduação de Arquitetura e Urbanismo na Universidade da Amazônia. Na Companhia de Desenvolvimento e Administração da Área Metropolitana de Belém - CODEM, ocupa o cargo de Diretora de Desenvolvimento Urbano desde janeiro de 2013. Tem experiência na área de Planejamento Urbano e Regional, com ênfase em estudos sobre cidades amazônicas, especialmente aqueles referentes: aos impactos urbanos de grandes projetos econômicos e de políticas de desenvolvimento regional; às configurações de estruturas interurbanas e intraurbanas; e, à construção de indicadores de qualidade de vida urbana.

Marco Aurélio Arbage Lobo - Doutor em Desenvolvimento Socioambiental. Professor titular da Universidade da Amazônia (UNAMA). Técnico de nível superior do Instituto Brasileiro de Geografia e Estatísticas (IBGE). Tem experiência na análise de dados sobre aspectos físico-ambientais e socioeconômicos do Planejamento Urbano e Regional, atuando principalmente nos seguintes temas: qualidade de vida, indicadores sociais, urbanização e desenvolvimento urbano. Também é consultor na área do Planejamento Urbano
} 
